\title{
A partnership of equals
}

\section{Stefan Oncents}

Over the past 20 years, a huge amount of effort has been invested into improving communication between doctors and their patients. Consultation courses with actors breaking down in tears, shouting, and slapping the doctor for the entertainment of those masters of the art are rife nowadays as we endeavour to improve the doctor-patient relationship and make health care a two-way street or, to be politically correct, a partnership.

It's unfair though that patients don't get the equivalent opportunity to learn. So to redress the balance I intend to set up a course for patients to learn how to present their problem to the doctor quickly and succinctly, and to learn the responses needed when asked a question, to ensure the smooth development of this doctor-patient partnership.

The first step is to learn how to listen to everything the doctor says, ideally with an expression commonly seen when a mother is cooing over her small baby, and to always reply: "Thank you doctor. You always know what's best. I'm so lucky to have you as my doctor". We'll be going over and over this until the response truly is Pavlovian. If it takes all day, so be it.

Once successfully through this stage - where patients will receive a certificate of completion, of course - we'll move on to the 'Now listen very carefully as I'm only going to say this once' section, or 'Mission Impossible' as it has been known in the past. Essentially this is teaching the patient about the critical appraisal process. So, for example, if asked when did you first notice this problem, the correct answer is not "when I got back from holiday" or "just before my friend's hen night" as many people will reply. Despite many patients thinking doctors live and breathe to know everything about a patient and therefore their social calendar, and that the patient is the only person who brings meaning to their doctor's life, becoming hugely jealous when others are seen in the waiting room, we all know this is not the case. The truth is as soon as the patient has left the consultation room the doctor will forget they exist such that it's a glazed look the patient receives when coming across their doctor beyond the boundaries of the practice 10 minutes later. This uncovering of reality can be distressing for some participants and so counsellors are always on hand to help wipe up the emotional fallout.

During this part of the course we'll also be covering how when asked about medication, the contraceptive pill, for example, replying "it begins with a ..." or "they're pink" is punishable by being kicked out of the clinic so in the interest of everyone's health and drawn-out legal battles it's best not to even contemplate these lazy responses.

There will also be education about questions the doctor asks that actually, despite seeming straightforward (although you wouldn't believe this judging by how long it takes someone to answer them), have an important role to play, other than helping the doctor make a diagnosis. Take, for example, the question: "When was your last

J Fam Plann Reprod Health Care 2009; 35(1): 61

The Peacetey King Surgery, Moorphoolsewe, UK Stefan Oncents, MRCGP, General Practitioner period?" Simple enough, isn't it? Well, no, many women take forever remembering this, something that's hard to fathom since periods appear to play such an important part of life, providing the substance for endless talk, problems and time off work. But the fact that this simple question launches a woman into dreamland, or into the lost world of her handbag searching for her diary, is actually a bonus for the doctor. Many a time I've been able to make use of this standstill of time to go and make a cup of tea, make some phone calls. Hell, once I even managed to do a home visit.

Now, let's not forget the guys and the question: "When did you last pass urine?" If the question instead was "When did you last take a dump?" then out would rush an enthusiastic answer describing not only the time but also the size, consistency and an encore of noises that accompanied the said motion. Ask about taking a leak, however, and off we journey to the land where time stands still again. Once back with the living the answer is likely to be: "This morning. Yeah. I think?" Not good enough mate. I want hours, minutes and seconds if I'm going to be able to play my part in diagnosing your STI accurately.

Of course we'll also be reviewing real-life case studies too. Patients will be asked to get into groups to examine an example consultation and using their newly acquired skills to critically assess what happened. A popular example with tutors - and all too familiar to participants - is the female patient who when attending at a GUM clinic is asked: "How can I help you today?" to which she replies: "I had unprotected sex with some guy I met last week", who when asked about what medication she takes replies: "It's in my notes", and then asked if she's taking anything else replies: "something from the health food shop". Her diagnosis of course is one that's very popular in sexual health: 'Don't care what you put inside you' syndrome.

In good old-fashioned general practice communication skills fashion they'll feed back. First, what they thought was good, and then what was not quite as good, and finally what wasn't too bad, but if it were them in the same situation this is how they might have done things differently. At this stage of the course it's very important that tutors watch out for any signs that participants are slipping back into the unhelpful mindset that they started the course with, that is, that they know best.

Throughout the course there will be regular breaks that will serve to teach patients that doctors too need fluid, and to use the toilet, and that despite what they might believe do not, and cannot, work solidly for 12 hours without leaving their high-backed leather swivel and reclining chair.

At the end of the course participants will be given a copy of an already completed course evaluation form to once again reinforce the take-home message that the doctor is always right and as a template to follow when they are asked to complete any practice satisfaction surveys.

Before leaving the course participants will be invited to spend a large sum of money each year to receive emails, a newsletter, and preferential rates for refresher and update courses by becoming paid-up members of the soon-to-beoversubscribed Patient Interactive Speech Society.

There, that's dealt with doctor-patient communication then. Now it's time to develop my 'Dog-training skills as applied to managing the PCT' course. 